\title{
Design Principles of a Responsive Pedagogical Model for Multimodal Skills of Oral Presentation
}

\author{
Lee Sze Seau \\ Education Department, Faculty of Social Sciences and Liberal Arts, \\ UCSI University, Kuala Lumpur, \\ Malaysia
}

\begin{abstract}
Within the scope of pedagogy, established methods have been found to be incongruous with the multimodal skills required of oral presentations in the $21^{\text {st }}$ century. Despite pedagogical innovations situated in native-speaking and advanced countries being so productive in experimenting with pedagogical techniques for various types of oral skills, multimodal skills of oral presentations have still been overlooked. The author is a practitioner in Malaysian higher education who struggles with this pedagogical dilemma in her daily professional life. Therefore, to respond to this practical issue and theoretical gap, the author designed a pedagogical model named the Responsive Multimodal Oral Presentation Pedagogy (RMO2P) to respond appropriately and proactively to the gap in oral presentation pedagogy. A practical action research that was based on McNiff \& Whitehead's (2011) action-reflection cycle was implemented in a tertiary Malaysian classroom for 13 weeks contributed to five applicable and theoreticallyinformed design principles of RMO2P which are based on the spirit of responsiveness. It is hoped that the explicit discussion on its design principles could inspire other teachers with no external funding and sophisticated technical expertise to embark on research for pedagogical improvement.

\section{KEYWORDS: Action Research, Higher Education, Multimodal, Oral Presentation Skills, Pedagogy}

\section{INTRODUCTION}

The concept of multiliteracies, a concept of literacy that highlights that literacy is multimodal rather than language dominant, could be traced back to the seminal paper written by the New London Group in 1996 (Anstey \& Bull, 2018; Early et al., 2015). In terms of multimodal literacies in oral presentations, Kress and Van Leeuwen (2001) could have been the first who pointed that oral presentations involve multimodality by suggesting that a presentation requires more than one
\end{abstract}


mode of semiotic representation. Many years later, discourse studies in higher education which indicate that EAP (English for Academic Purposes) class presentations require voice projection, making eye contact, engaging body gestures, using visual aids, the appropriate presentation structure and linguistic knowledge (Januin \& Stephen, 2015) suggest that multimodal literacies are indeed being engaged frequently in the classroom. Therefore, multimodal oral presentation skills are a part of the 21 st century communication repertoire which requires the manipulation of multiple modalities (Barrett \& Liu, 2016; Cope \& Kalantzis, 2015; Kress, 2010).

One issue that calls for attention pertains to oral presentation pedagogy. Methods for teaching oral presentation skills have been explored for decades, yet established methods do not target the multimodal skills required of oral presentations in the $21^{\text {st }}$ century. Established methods such as Audiolingualism and CLT (Communicative Language Teaching) neglect certain aspects of nonverbal behaviour that are critical for delivering oral presentations such as content development, visual design and eye contact (Allen \& Paesani, 2010; Larsen-Freeman \& Anderson, 2011). Ultimately, the pedagogical problem that needs to be addressed is that students are required to engage multimodal literacies, but they are not taught effectively to do so in the classroom (Hung et al., 2013). Barrett and Liu (2016) confirmed that to date, there is no theoretically-backed instructional approach that addresses the multimodal skills required of oral presentations. Given the high stakes oral presentations carry for academic success (Barrett \& Liu, 2016) and employability (Abdullah-Adnan \& Adelina, 2018), the author posits that the gap in oral presentation pedagogy requires intervention.

Although there have been constant developments of pedagogical innovations for various types of oral skills, interventions are still highly anticipated, especially in Malaysian higher education and for multimodal oral presentation skills. At the higher education level, there is a growing inclination towards engaging technologies such as wiki (Ainol \& Zailin, 2012) and multimedia courseware (Tsai, 2010). Nonetheless, these studies have mostly been completed in native-speaking and advanced countries such as USA and Canada ( $\mathrm{Su}, 2015)$ while multimodal oral presentation skills have been generally neglected (Barret \& Liu, 2016). Moreover, a systematic review of current research on oral skills situated in Malaysian higher education shows that there is a need for more designs and implementations of pedagogical innovations (elaborated in next section). While only several studies developed pedagogical interventions for oral presentations, interventions for multimodal oral presentation skills were not identified. The lack of pedagogical innovations in Malaysian higher education for oral presentations is a regrettable situation especially since local surveys have underlined the need for more pedagogical interventions (e.g. Hafizoah \& Fatimah, 2010). In fact, the Malaysian government has also pushed for educators to initiate curricular and pedagogical innovations which aim to improve the oral skills of Malaysian graduates (Ministry of Higher Education, 2012).

The author is a practitioner in Malaysian higher education who struggles with the responsibility of enhancing the learning of oral presentation skills among her students in her daily professional life. Therefore, the Responsive Multimodal Oral Presentation Pedagogy (RMO2P) is a pedagogical model which was designed to respond appropriately and with interest to the gap in oral presentation pedagogy. This pedagogical gap that relates to multimodal literacies in oral presentations is significant in the author's classroom and as the introduction has suggested, also resonates at the national and global levels. Practical action research provided a relevant framework to synthesise theory with empirical observations of a natural setting to design an effective pedagogical model 
that aims to enhance learning. While preliminary analysis of interviews indicated that RMO2P impacted student abilities in multimodal oral presentation skills, self-awareness and affective experience (Lee et al., 2018), the following research question highlights the scope covered in this paper:

What are the design principles of a responsive pedagogical model for multimodal skills of oral presentations?

\section{LITERATURE REVIEW}

A systematic review of current research on oral skills situated in Malaysian higher education was attempted to situate the study. The review only considered peer-reviewed articles which were based on empirical studies and published from the year 2000 onwards. Due to limited studies on oral presentation skills in Malaysian higher education, categories beyond oral presentations such as oral interactions were included as long as the research involved tertiary students.

The review resulted in 15 studies on oral skills situated in Malaysian higher education which reflect a dispersed trend. Certain studies focused on discipline-specific oral skills such as technical oral presentations for engineers (e.g., Bhattacharyya \& Zainal, 2015) and aviation-specific speaking skills (Paramasivam, 2013). Some studies investigated interventions for oral interaction (Ting et al., 2010; Williams \& Yah, 2013). Only six studies focused on oral presentations taught in the EAP context, which is similar to the focus of this study, although some of them refer to oral presentation skills as public speaking skills (e.g., Hafizoah et al., 2015).

The methods behind the reported pedagogical interventions range from the communicative method to the lesser-known eclectic models. Williams and Yah (2013) experimented with the communicative method. Ting et al. (2010) referred to a genre-based method while Nadzrah et al. (2013) experimented with asynchronous online discussions to provide more opportunities for practice and self-paced learning. Paramasivam (2013) developed aviation-specific speaking materials by synthesising a number of studies. Hafizoah et al. (2015) designed a Creative Strategy Learning Model which positively impacted students' thinking and creativity. Blended learning was recommended for speech preparation (Ainol \& Zailin, 2012). There were also experimentations with video blogging which improved student perceptions of public speaking skills (Balakrishnan \& Fatimah, 2014), and Pecha Kucha which was reported to be conducive for collaboration and developing skills by teachers and students (Murugaiah, 2016).

Apart from developing pedagogical interventions, there is another preoccupation in Malaysian higher education with surveying the stakeholders' perceptions on students' oral competence or identifying areas that pedagogical interventions need to address. While this study focuses on the multimodal aspects of oral presentations, these surveys have highlighted the linguistic aspects. For instance, the surveys indicated student performances are affected by anxiety, English proficiency and knowledge (e.g., Noor Raha \& Kaur, 2011). Certain linguistic and rhetorical dimensions of communicative competence have been highlighted by engineering students (Bhattacharyya \& Zainal, 2015). Common linguistic errors made by students - such as articles, verb forms and word forms - were also identified (Ainon et al., 2013; Ting et al., 2010).

Besides ascertaining the lack of pedagogical interventions in Malaysian higher education, the review also confirmed that there was no research conducted in the Malaysian higher education 
setting which addressed multimodal skills of oral presentations, a set of skills necessary for the $21^{\text {st }}$ century which have been explained in the introduction. When the global research landscape was examined, it was discovered that most of the available studies also largely focused on examining individual techniques instead of exploring the impact of orchestrating a few techniques through a coherent approach (Van Ginkel et al., 2015). Developing a pedagogical method for the teaching of multimodal skills required of oral presentations is hence theoretically significant.

With the aim of being responsive to the pedagogical and theoretical gap, the author proposes that the Sociocultural Theory of Learning or SCT (Vygotsky, 1978) and the Pedagogy of Multiliteracies (Cope \& Kalantzis, 2015) could provide basic guidelines for the design of a pedagogical model. As a conventional framework which is familiar to ESL teachers, SCT (Vygotsky, 1978) is responsive to the students' sociocultural background and recommends the teacher to consistently adjust the required scaffolding. In contrast, the Pedagogy of Multiliteracies (Cope \& Kalantzis, 2015) is a more recently developed framework which is responsive to the multimodal nature of the $21^{\text {st }}$ century communication landscape. The discussion would elaborate how SCT and the Pedagogy of Multiliteracies were integrated into the pedagogical model.

\section{METHODOLOGY}

The author played the role of a teacher-researcher who attempted a practical action research in a tertiary Malaysian classroom to design RMO2P which was implemented in a classroom for 13 weeks. Practical action research provides a systematic framework for the practitioner to reflect upon practice (Mills, 2014).

\section{$\underline{\text { Participants }}$}

Apart from the teacher-researcher who played the role of participant-observer, purposeful sampling which is typical of action research (Hendricks, 2017) determined the selection of 20 student participants. The participants were Degree in Media Studies students who enrolled in a compulsory Public Speaking Course. The profiling questionnaire indicated that their age ranged from 19 to 22 years old and they had a multilingual language profile like an average Malaysian Chinese student. The students spoke Mandarin, English, Malay, in addition to at least on Chinese dialect. Their SPM (Malaysian Education Certificate) English exam scores which were mostly B or $\mathrm{C}$ suggested that their abilities in the English language were heterogeneous. They were familiar with the use of the internet and were active on social media. The student participants contributed to the design and development of RMO2P by learning under the guidance of this pedagogical model in a natural setting.

The teacher-researcher was a full participant in the study by developing RMO2P and implementing it to teach the student participants while evaluating it. As the participant-observer, the teacherresearcher provided emic perspectives through writing a reflection diary. The action-reflection cycle (McNiff \& Whitehead, 2011) guided the reflection process.

\section{Research Process}

The study was based on McNiff \& Whitehead's (2011) action-reflection cycle which involves the observe-reflect-act-evaluate-modify processes. Table 1 depicts how the pedagogical model (RMO2P) was developed based on the research activities which were carried out at each stage of the research process. 
Table 1. Research Process and the Development of RMO2P

\begin{tabular}{|c|c|}
\hline $\begin{array}{l}\text { Research Process based on Action- } \\
\text { reflection cycle (McNiff \& Whitehead } \\
\text { 2011) }\end{array}$ & Development of RMO2P \\
\hline \multicolumn{2}{|l|}{ Pre-implementation (13 weeks) } \\
\hline Observe & $\begin{array}{l}\text { Identified the pedagogical issue which should be addressed by } \\
\text { RMO2P based on the teacher-researcher's personal reflections, } \\
\text { study of documents, informal conversations with } 20 \text { graduated } \\
\text { students and } 3 \text { teachers from the site of study, and literature } \\
\text { review }\end{array}$ \\
\hline Reflect & $\begin{array}{l}\text { Designed RMO2P by synthesising the Pedagogy of } \\
\text { Multiliteracies (Cope \& Kalantzis, 2015) and the principles of } \\
\text { semiotic mediation from SCT (Vygotsky, 1978) with four } \\
\text { pedagogical techniques }\end{array}$ \\
\hline \multicolumn{2}{|l|}{ During implementation (13 weeks) } \\
\hline Act & Implemented RMO2P in the classroom \\
\hline Evaluate & $\begin{array}{l}\text { Evaluated the impact of the pedagogical model through } \\
\text { analysing multiple sources of data }\end{array}$ \\
\hline \multicolumn{2}{|l|}{ Post-implementation ( 4 weeks) } \\
\hline (2) & $\begin{array}{l}\text { Delineated the design and pedagogical principles of RMO2P } \\
\text { for future implementation based on the evaluation. }\end{array}$ \\
\hline
\end{tabular}

The evaluation was based on triangulating multiple sources of data such as descriptive statistics generated from a pre-test and a post-test, interviews with students, teacher-researcher's reflection diary and Facebook tasks which students completed. The result of completing this research process was a clearly delineated pedagogical model of RMO2P which was informed by theoretical framework and validated through action research. The next section would discuss the design principles of RMO2P which were inferred after completing one cycle of action research.

\section{FINDINGS AND DISCUSSION}

Thus far, it has been established that the author played the role of the teacher-researcher to respond to the perceived gap in the pedagogy for oral presentation skills by undertaking a practical action research. The pedagogical gap has both practical consequence and theoretical significance. Based on one cycle of implementation, this paper aims to address this research question: What are the design principles of a responsive pedagogical model for multimodal skills of oral presentations? The discussion of findings would be organised under five applicable and theoretically-informed design principles of the pedagogical model (RMO2P) which are based on the spirit of responsiveness. Pseudonyms would be used to refer to the participants to protect their privacy.

Design Principle 1: Systematically Identify the Multimodal Components of Oral Presentation $\underline{\text { Skills }}$

The author proposes that there is a need to systematically identify the components of multimodal oral presentation skills due to lack of theoretically-backed instructional approaches (Barrett \& Liu, 2016) and ambiguous specifications of the factors which contribute to successful presentations (Tsang, 2020). Studies which designed rubrics to assess oral presentation performance in higher education proposed strategies such as referring to existing samples and requesting feedback from stakeholders (e.g., Schreiber et al., 2012; Van Ginkel et al., 2017). RMO2P adapted these strategies to identify a set of multimodal skills required of oral presentations which were applicable to ESL students in Malaysian higher education by: 1) analysis of rubrics from empirical research, textbooks and Malaysian tertiary institutions, and 2) validation by three Malaysian experts. 
Ten multimodal components of oral presentation skills were identified for delivering informative speeches in groups at the Malaysian tertiary level. These components were further classified under three sub-categories: content and structure, delivery and team dynamics. Under content and structure, the components were introduction, content, organisation and conclusion. Delivery included components such as linguistic ability, oral ability, visual engagement ability, gestural ability and overall credibility. Lastly, team dynamics referred to coordination.

\section{Design Principle 2: Develop a Strong Awareness of Contextual Realities}

To design a relevant pedagogical method, the teacher-researcher responded appropriately and readily with interest by making an appropriate selection of theories to guide its design while being strongly aware of the available resources and contextual realities of the natural setting. Aspects of considerations included curriculum structure, available resources, size of classes and available support.

The natural setting's curriculum structure stipulated only one oral presentation course for the degree students which spanned 13 weeks excluding revision and exam weeks, and weekly contact time of 2.5 hours. The teacher-researcher usually worked independently without any technical support although the number of students per class was often small (less than 30 students). The available resources were the textbooks supplied in the college library such as Lucas (2007). Although more updated publications and other textbooks are available now, at the point of study, Lucas (2007) was the main textbook available. To supplement the textbook with more updated materials, the teacher-researcher engaged online resources such as TED videos (available from https://www.ted.com/talks) because the students were connected with the internet out of school.

Design Principle 3: Synthesise Appropriate Theories to Create a Robust Theoretical Foundation With a strong awareness of these contextual realities and the theoretical gap for oral presentation pedagogy, the teacher-researcher tried to select appropriate theories to form a strong foundation for the pedagogical model. This was a fundamental step due to the lack of guiding frameworks.

The teacher-researcher was attracted to SCT (Vygotsky, 1978), whose proponents made a strong case for teachers to modify instructional conditions to encourage learning. In specific, learning within ZPD (Zone of Proximal Development) requires the teacher "intervening and creating conditions for development" (Lantolf et al., 2015, p. 207). The teacher could create conditions that could provide cognitive, affective and social support to learners (Kim, 2013). The teacherresearcher heeded the suggestions that there are many semiotic tools beyond speech which the teacher could engage (Vygotsky, 1981), such as technology (Kim, 2013) and teacher feedback (Talley, 2014).

However, since there are also no 'default' models in learning within ZPD (Vygotsky, 1978), the design of a responsive pedagogical model required synthesis with other theories. The Knowledge Processes (Cope \& Kalantzis, 2015) informed the design of the stages of learning and learning activities in RMO2P. The stages of learning in RMO2P is a manifestation of learning as "a process of 'weaving' backwards and forwards, across and between different pedagogical moves" (Cope \& Kalantzis, 2015, p. 4). Table 2 depicts in summary how various pedagogical moves were weaved to create the stages of learning in RMO2P. Similar to past studies which adapted the Knowledge Processes for their own contextual needs (e.g., Angay-Crowder et al., 2013), the Knowledge Processes were interpreted in a fluid manner instead of as a fixed linear sequence. The proposed 
stages of learning provide a structured plan for the teacher to monitor and adjust scaffolding which mediates learning (Smagorinsky, 2011).

Table 2. Weaving Pedagogical Moves from the Knowledge Processes into the Stages of Learning in RMO2P

\begin{tabular}{|c|c|c|}
\hline $\begin{array}{l}\text { Stage of Learning } \\
\text { (Week) }\end{array}$ & $\begin{array}{l}\text { Pedagogical Moves Involved } \\
\text { (Cope \& Kalantzis, 2015) }\end{array}$ & Pedagogical Focus \\
\hline $\begin{array}{l}\text { Stage 1 } \\
\text { (Week 1): } \\
\text { Conceptualising } \\
\text { Multimodal Oral } \\
\text { Presentations }\end{array}$ & $\begin{array}{l}\text { Experiencing the known and } \\
\text { Conceptualising by naming }\end{array}$ & $\begin{array}{l}\text { - Conceptualise the oral presentation as a } \\
\text { multimodal design by drawing upon prior } \\
\text { knowledge and perspectives. }\end{array}$ \\
\hline $\begin{array}{l}\text { Stage } 2 \\
\text { (Week 2): } \\
\text { Conceptualising } \\
\text { Self }\end{array}$ & $\begin{array}{l}\text { Experiencing the known and } \\
\text { Analysing functionally }\end{array}$ & $\begin{array}{l}\text { - Conceptualise and analyse their own } \\
\text { abilities in delivering multimodal oral } \\
\text { presentations. }\end{array}$ \\
\hline $\begin{array}{l}\text { Stage } 3 \\
\text { (Week 3): } \\
\text { Analysing }\end{array}$ & $\begin{array}{l}\text { Experiencing the new and } \\
\text { Analysing functionally }\end{array}$ & $\begin{array}{l}\text { - Immerse in a new way to deliver oral } \\
\text { presentations through model } \\
\text { presentations, which can be virtual. } \\
\text { - Analyse presentations in terms of } \\
\text { purpose, structure and demonstration of } \\
\text { oral presentation skills using concept } \\
\text { maps. }\end{array}$ \\
\hline $\begin{array}{l}\text { Stage } 4 \\
\text { (Weeks } 4 \text { to } 10) \text { : } \\
\text { Scaffolding through } \\
\text { Applying Concepts }\end{array}$ & $\begin{array}{l}\text { Experiencing the new, } \\
\text { Conceptualising with theory, } \\
\text { Analysing functionally and } \\
\text { Applying appropriately }\end{array}$ & $\begin{array}{l}\text { - Multimodal oral presentation skills are } \\
\text { unpacked into discrete skills so that the } \\
\text { scaffolding of the knowledge and abilities } \\
\text { in these skills could be gradually } \\
\text { experienced. } \\
\text { - Illustrate conceptual knowledge with } \\
\text { concept maps through experiential } \\
\text { processes. } \\
\text { - Apply conceptual knowledge into } \\
\text { scaffolding each multimodal component } \\
\text { of oral presentation skills and analysing } \\
\text { model presentations. }\end{array}$ \\
\hline $\begin{array}{l}\text { Stage } 5 \\
\text { (Weeks } 11 \text { to } 12) \text { : } \\
\text { Designing }\end{array}$ & $\begin{array}{l}\text { Analysing functionally and } \\
\text { Applying appropriately }\end{array}$ & $\begin{array}{l}\text { - Apply conceptual knowledge into } \\
\text { designing and analysing presentation } \\
\text { outlines. }\end{array}$ \\
\hline $\begin{array}{l}\text { Stage } 6 \\
\text { (Week 13): } \\
\text { Performing }\end{array}$ & $\begin{array}{l}\text { Applying creatively } \\
\text { Analysing critically }\end{array}$ & $\begin{array}{l}\text { - Perform oral presentations multimodally } \\
\text { based on outlines. } \\
\text { - Analyse performances. }\end{array}$ \\
\hline
\end{tabular}

Under each stage of learning, various activities which could be carried out to mediate learning were also designed. Activities which entail more active engagement of students such as games were discovered from the New Learning Website (Cope \& Kalantzis, 2013). Besides using conventional textbooks as materials (Lucas, 2007), The New Learning Website (Cope \& Kalantzis, 2013) provided a reference point for concept maps which have been incorporated as semiotic tools that mediate participation (Vygotsky, 1981).

In summary, the theoretical foundation of RMO2P was grounded by the synthesis of SCT (Vygotsky, 1978) with the Knowledge Processes from the Pedagogy of Multiliteracies (Cope \& 
Kalantzis, 2015). SCT guided the teacher's responsive behaviour and nature of scaffolding while the Pedagogy of Multiliteracies informed the design of six stages of learning, learning activities and concept maps.

\section{Design Principle 4: Integrate the Most Appropriate Techniques to Mediate Learning}

In addition to the weaving of eight pedagogical moves (Cope \& Kalantzis, 2015) to create six stages of learning of RMO2P and the weaving of activities and materials within each stage to mediate learning, four techniques which could mediate learning were also weaved into RMO2P. Techniques such as videos, Web 2.0, collaborative learning and feedback were weaved into the pedagogical method as various forms of scaffolding. The nature of this integration would be illustrated through two instances.

In Week 2 (Conceptualising Self Stage), the students were guided to develop an accurate selfawareness of themselves as presenters through the integration of self-recorded videos, collaborative learning, Web 2.0 and feedback. The self-recorded videos documented the students' first group oral presentations while Facebook provided a convenient Web 2.0 platform for students to access these videos and analyse their strengths and weaknesses. A simple instruction was given to the students: Write about at least one strength and/ weakness that you notice in your own performance. Minnie, who is typically shy and hardly asked any question in class wrote: "Feel embarrassed to review what we did but it's also a good way to see clearly that the parts we need to improve ... we have wonderful slides and we have team spirit. The weakness are we are not confident, referring paper, standing postures and also not fluently speaking. Hope we can do better in next time" (unedited Facebook post). The convenience and interactivity of Web 2.0 also allowed the teacher-researcher to convey individualised feedback. The following unedited excerpt from Facebook provides a sample of individualised feedback to a student's analysis of own performance:

Yen: $\quad$ Strength - show videos for example, loud voice, a little bit creativity. Weakness - looks and sound nervous, not well prepare, body language (should stand properly and look steady), grammar problem, less eye contact with audience, reading from the slide, not give a clear example.

Teacher: $\quad$ Yen, you need to be clearer on what the video's aim is so that the audience is more focused.

The reflection diary recorded that students' analyses demonstrated increased self-awareness of their multimodal oral presentation abilities and enhanced engagement including the more introverted students. Hence, these learning outcomes could be the combined impacts of multiple techniques such as videos and teacher feedback which were made available through Facebook.

While the previous instance (Week 2: Conceptualising Self Stage) elaborated how teacher feedback could be focused on the individual student, the next instance would demonstrate how teacher feedback addressed concerns raised at class level during face-to-face interactions in class.

When the students developed conceptual knowledge about content development in Week 4, only two techniques - collaborative learning and feedback - were integrated. In collaborative groups of four, the students completed a concept map to acquire the principles of content development from the textbook (Lucas, 2007). Then, the students evaluated selected internet articles as sources of 
information. There were some questions that teacher feedback addressed: What is the difference between paraphrase and quotation? How do I find out if the author is credible? Teacher feedback also intervened in instances when students showed misinterpretations. For example, some students wrongly assumed that authors without a doctorate were not credible. Teacher feedback offered suggestions on how to evaluate internet articles and author credibility by highlighting the following strategies: 1) Google the author to discover or confirm achievements and expertise; 2) Look for accreditation of the website; 3) Check the authenticity and formatting of the references listed by the author. In this illustration of technique integration, there was no involvement of videos or Facebook, but teacher feedback clearly complemented collaborative learning in class. As a result, students were more critically engaged and increased their conceptual knowledge on content development.

In summary, through the descriptions of two learning instances, it has been justified how the variable integration of four techniques in RMO2P could impact student's self-awareness of abilities, engagement and development of multimodal oral presentation skills. While Hafizoah et al.'s (2015) pedagogical intervention excluded component skills such as content, organisation, grammar and pronunciation, RMO2P addressed conceptual knowledge and self-awareness. Although feedback is the consistent technique present in RMO2P, the author would like to posit that it is the effective integration of feedback with collaborative learning, videos and Web 2.0 which provide the necessary scaffolding in terms of cognitive, affective and social support to learners (Kim, 2013). Extending the relationship highlighted between feedback and affective experience (Van Ginkel et al., 2017), this study recommends for teacher feedback to be intense, comprehensive and individualised when appropriate. Facebook as a Web 2.0 tool facilitated these characteristics in teacher feedback and enabled interactivity with students in teacher feedback. Consequently, teacher feedback conveyed promise in enhancing self-awareness among students when integrated effectively with task design, when previous literature did not explore the impact of feedback (e.g., Murugaiah, 2016; Nadzrah et al., 2013; Paramasivam, 2013).

\section{Design Principle 5: Anticipate Multiple Layers of Integration in the Instructional Design}

In the attempt to design a pedagogical method, the instructional design would most probably require multiple layers of integration instead of a mono-directional application of a singular framework.

In the design of RMO2P, the first layer of weaving was in designing the theoretical framework which was a synthesised framework consisting the Pedagogy of Multiliteracies (Cope \& Kalantzis, 2015), SCT (Vygotsky, 1978) and four techniques discovered through literature review. Furthermore, other layers of weaving involved how the techniques would be incorporated, the pedagogical moves within each stage of learning, as well as the activities and materials within each stage. The instructional design of the Analysing Stage (Table 3) would be explained to illustrate the layers of weaving involved.

Table 3. Instructional Design of the Analysing Stage

\section{Stage 3: Analysing}

based on Experiencing the new and Analysing functionally (Cope \& Kalantzis, 2015) 


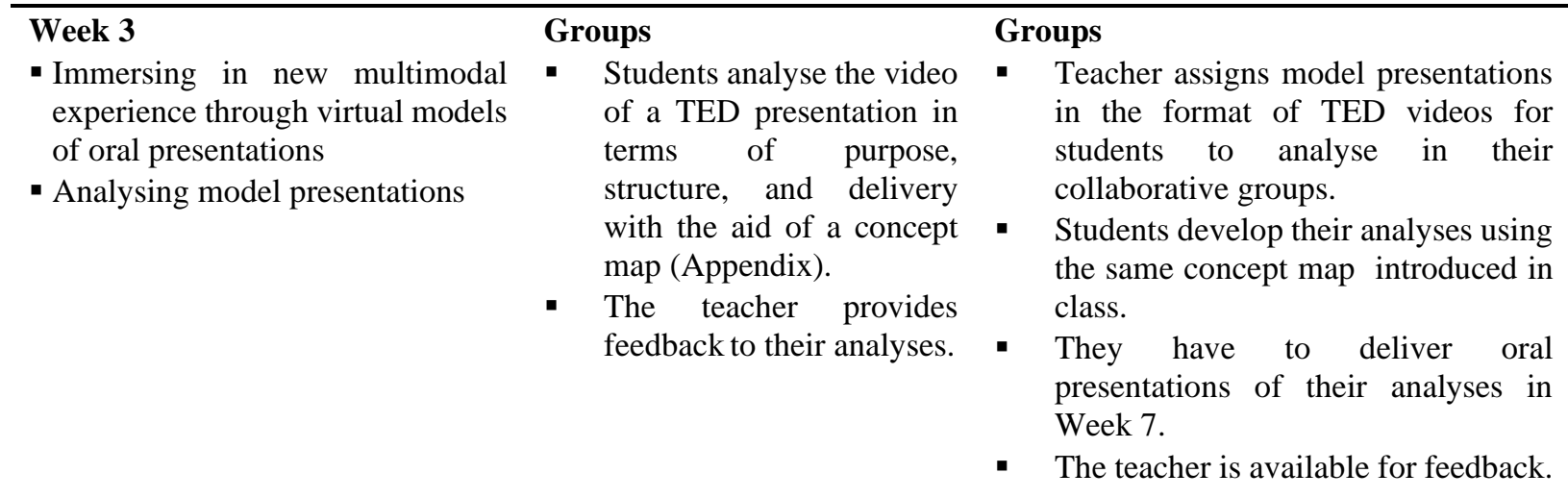

The Analysing Stage was based on two pedagogical moves from the Knowledge Processes (Cope \& Kalantzis, 2015), Experiencing the new and Analysing functionally. The pedagogical focus was for students to experience new ways of delivering presentations and analyse model presentations. In terms of techniques, videos, collaborative learning, feedback and Web 2.0 were integrated to mediate learning. In class, the students were guided to view a video of a TED presentation and collaboratively analyse this presentation as a model. A concept map (Appendix) was engaged to assist the formation of these analyses. The teacher-researcher provided immediate feedback which scaffolded the learning of the metalanguage for analysing oral presentations when the students asked questions about some terms that were commonly used. The terms that needed clarification included organisation, connectives, the difference between oral ability and linguistic ability, and the distinction between content development and conviction.

After class, the teacher-researcher utilised Facebook's properties as a Web 2.0 tool to upload more videos of model presentations from TED for students to collaboratively analyse out of class. Students collaboratively delivered their analyses in class in Week 7 and received feedback both in class and through Facebook. The reflection diary noted that Facebook allowed the students to access the videos conveniently and pre-watch the presentations before attending class so that they could focus on listening to other groups' analyses. Facebook was also effective for the delivery of teacher feedback which targeted whole group performance or individual performance. The following is a sample of the comprehensive feedback which could be given to one collaborative group:

Teacher: $\quad$ As a group, 1) you can try to be even more effective with slide design. Eg. The charts that show the different abilities could be further differentiated into strengths and weaknesses. Perhaps use different colours for both? 2) Check your content. Make sure each claim is supported by clear and convincing examples.

Yee is strong in the use of voice and gestures. But you need to work on the language accuracy.

Timmy is clever to draw our attention to the chart that sums up the content. His language accuracy is again his weakest area.

Dee needs to be very careful with her articulation. At times I cannot understand what she is saying without looking at the slides. Overuse of 'then next'. 
Isaac, please keep your confidence. Work on being even more dramatic when appropriate and your language accuracy.

Hence, the Analysing Stage is a vivid illustration of the multiple layers of integration in RMO2P. The integration is an applied interpretation of the kind of responsive scaffolding which the teacher could create, where various semiotic tools could be engaged (Vygotsky, 1981), including technology (Kim, 2013) and teacher feedback (Talley, 2014).

The students' oral analyses (Week 7) showed that they had increased their conceptual knowledge to a large extent. Students supported their views with convincing examples and references, and showed overall improvement in PowerPoint design. The less effective slides showed points presented in lists when diagrams would have been more effective. Several students even demonstrated obvious improvement in the use of voice and gestures. The findings on the learning outcomes of RMO2P could complement other intervention designs, such as those that investigated participant perceptions (Balakrishnan \& Fatimah, 2014; Murugaiah, 2016) and those that focused on other aspects apart from multimodal skills (Ainol \& Zailin, 2012; Hafizoah et al., 2015; Nadzrah et al., 2013).

\section{CONCLUSION}

A practical action research was attempted by the author as a responsive resolve to the theoretical and pedagogical gap perceived in oral presentation pedagogy. The resolve resulted in the author designing RMO2P as a pedagogical model which could be adopted or adapted for the teaching of oral presentation skills. For instance, the teacher-researcher discovered after data collection that activities conducted through Facebook could be adapted for reliable LMS platforms (Learning Management Systems). The findings discussed in this paper suggested that students enhanced selfawareness, conceptual knowledge of multimodal oral presentation skills, engagement and affective experience.

Although the research design of an action research inherently limits generalisation, the impact on students has significant implications for both practice and research, considering there is limited research in Malaysian higher education which addresses multimodal skills of oral presentations, a set of skills necessary for the 21 st century. The discussion of the five design principles of RMO2P would hopefully guide practitioners who empathise with the author's professional predicament, such as the lack of funding and sophisticated technical expertise. RMO2P is most suitable for practitioners who are committed to enhancing pedagogy in small classes through engaging theory.

\section{REFERENCES}

Abdullah-Adnan, M., \& Adelina, A. (2018). Understanding engineering undergraduates' technical oral presentation: Challenges and perspectives. International Journal of Language Education and Applied Linguistics, 8(1), 41-53. https://doi.org/10.15282/ijleal.v8.529

Ainol H. I., \& Zailin, S. Y. (2012). Teaching public speaking in a blended learning environment. International Journal of Social Science and Humanity, 2(6), 573-576. https://doi.org/10.7763/IJSSH.2012.V2.175

Ainon, J. M., Mohd. Ismail, A. S., Engku Haliza, E. I., Isarji, S., Faridah, A. M., \& Rozina, A. G. (2013). Oral presentation errors of Malaysian students in an English for Academic Purposes

(EAP) course. World Applied Sciences Journal, 21, 19-27. https://doi.org/10.5829/idosi.wasj.2013.21.slt1.2133 
Allen, H.W., \& Paesani, K. (2010). Exploring the feasibility of a pedagogy of multiliteracies in introductory foreign language courses. L2 Journal, 2(1), 119-142. https://doi.org/10.5070/L2219064

Angay-Crowder, T., Choi, J., \& Yi, Y. (2013). Putting multiliteracies into practice: Digital storytelling for multilingual adolescents in a summer program. TESL Canada Journal, 30(2), 36-45.

Anstey, M., \& Bull, G. (2018). Foundations of multiliteracies: Reading, writing and talking in the 21st century. Routledge.

Balakrishnan, V. M., \& Fatimah, P. (2014). Blending face-to-face communication and video blogging in acquiring public speaking skills. Journal of Creative Practices in Language Learning and Teaching, 2(1), 64-72.

Barrett, N. E., \& Liu, G. Z. (2016). Global trends and research aim for English academic oral presentations: Changes, challenges, and opportunities for learning technology. Review of Educational Research, 20(10), 1-45. https://doi.org/10.3102\%2F0034654316628296

Bhattacharyya, E., \& Zainal, A. Z. (2015). What do students and engineers have to say about communicative competence in technical oral presentations? Pertanika Journal of Social Science \& Humanities, 23, 123-142.

Cope, B., \& Kalantzis, M. (2013). New learning: transformational designs for pedagogy and assessment. http://newlearningonline.com/new-learning.

Cope, B., \& Kalantzis, M. (2015). The things you do to know: An introduction to the pedagogy of multiliteracies. In: Cope, B., Kalantzis, M. (eds) A pedagogy of multiliteracies, London, England: Palgrave Macmillan, pp. 1-36.

Early, M. Kendrick, M., \& Potts, D. (2015). Multimodality: Out from the margins of English language teaching. TESOL Quarterly, 49, 447-460. https://doi.org/10.1002/tesq.246

Hafizoah K., \& Fatimah, A. (2010). English communicative events and skills needed at the workplace: Feedback from the industry. English for Specific Purposes, 29, 168-182. http://dx.doi.org/10.1016/j.esp.2009.10.002

Hafizoah, K., Najah, O, \& Aziman, A. (2015). Creative strategy: A pilot evaluation of a hypothetical learning model through public speaking performance. Procedia - Social and Behavioral Sciences, 171, 919-928. https://doi.org/10.1016/j.sbspro.2015.01.210

Hendricks, C. (2017). Improving schools through action research: A reflective practice approach (4th ed.). Pearson.

Hung, H. T., Chiu, Y. C. J., \& Yeh, H. C. (2013). Multimodal assessment of and for learning: A theory-driven design rubric. British Journal of Educational Technology, 44, 400-409. https://doi.org/10.1111/j.1467-8535.2012.01337.x

Januin, J., \& Stephen, J. (2015). Exploring discourse competence elements in EAP class presentations through document and ethnographic analyses. Procedia - Social and Behavioral Sciences, 208, 157-166. https://doi.org/10.1016/j.sbspro.2015.11.192

Kim, M. S. (2013). Technology-mediated collaborative learning environments for young culturally and linguistically diverse children: Vygotsky revisited. British Journal of Educational Studies, 61(2), 221-246. https://doi.org/10.1080/00071005.2012.745480

Kress, G. (2010). Multimodality: A social semiotic approach to contemporary communication. Taylor \& Francis.

Kress, G., \& Van Leeuwen, T. (2001). Multimodal discourse: The modes and media of contemporary communication. Arnold. SE-pi

Lantolf, J. P., Thorne, S. L., \& Poehner, M. E. (2015). Sociocultural theory and second language 
development. Theories in second language acquisition: An introduction, 1, 207-226.

Larsen-Freeman, D., \& Anderson, M. (2011). Techniques and principles in language teaching (3rd ed.). Oxford University Press.

Lee, S. S., Azman, H., \& Md. Noor, N. (2018). A responsive pedagogical initiative for multimodal oral presentation skills: an action research study. 3L: The Southeast Asian Journal of English Language Studies, 24(2), 29-42. http://doi.org/10.17576/3L-2018-2402-03

Lucas, S. E. (2007). The art of public speaking (9th ed.). McGraw-Hill Higher Education.

McNiff, J., \& J. Whitehead. (2011). All you need to know about action research (2nd ed.). Sage Publications.

Mills, G. E. (2014). Action research: A guide for the teacher researcher (5th ed.). Pearson.

Ministry of Higher Education. (2012). The National Graduate Employability Blueprint 20122017. Putrajaya, Malaysia.

Murugaiah, P. (2016). Pecha Kucha style PowerPoint presentation: An innovative call approach to developing oral presentation skills of tertiary students. Teaching English with Technology, 16(1), 88-104.

Nadzrah A. B., Hafizah, L., \& Afendi, H. (2013). Enhancing ESL learners speaking skills through asynchronous online discussion forum. Asian Social Science, 9(9), 224-233. https://doi.org/10.5539/ass.v9n9p224

Noor Raha, M. R., \& Kaur, S. (2011). Technical oral presentations in English: Qualitative analysis of Malaysian engineering undergraduates' sources of anxiety. Procedia- Social and Behavioural Sciences, 29(201), 1436-1445. https://doi.org/10.1016/j.sbspro.2011.11.383

Paramasivam, S. (2013). Materials development for speaking skills in aviation English for Malaysian air traffic controllers: Theory and practice. The Journal of Teaching English for Specific and Academic Purposes, 1(2), 97-122.

Schreiber, L. M., Paul, G. D., \& Shibley, L. R. (2012). The development and test of the Public Speaking Competence Rubric. Communication Education, 61(3), 205-233. https://doi.org/10.1080/03634523.2012.670709

Smagorinsky, P. (2011). Vygotsky and literacy research: A methodological framework. Sense.

$\mathrm{Su}, \mathrm{Y} . \mathrm{R}$. (2015). An overview of the development of research on public speaking course from 2004 to 2013. Chinese Journal of Applied Linguistics, 38(4), 415-434. https://doi.org/10.1515/cjal-2015-0027

Talley, P. C. (2014). Students' responses to scaffolded learning in the Asian University ESL classroom. International Journal of Business and Social Science, 5(3), 235-244.

Ting, S. H., Mahadhir, M., \& Chang, S. L. (2010). Grammatical errors in spoken English of university students in oral communication course. GEMA Online Journal of Language Studies, 10(1), 53-70.

Tsai, S. C. (2010). Developing and integrating courseware for oral presentations into ESP learning contexts. Computers \& Education, $\quad 55, \quad 1245-1258$. https://doi.org/10.1016/j.compedu.2010.05.021

Tsang, A. (2020). Enhancing learner's awareness of oral presentation (delivery) skills in the context of self-regulated learning. Active Learning in Higher Education, 21(1), 39-50. https://doi.org/10.1177\%2F1469787417731214

Van Ginkel, S., Gulikers, J., Biemans, H., \& Mulder, M. (2015). Towards a set of design principles for developing oral presentation competence: A synthesis of research in higher education. Educational Research Review, 14, 62-80. https://doi.org/10.1016/j.edurev.2015.02.002

Van Ginkel, S., Gulikers, J., Biemans, H., \& Mulder, M. (2017). The impact of the feedback source 
Design Principles of a Responsive Pedagogical Model for Multimodal Skills of Oral Presentations

on developing oral presentation competence. Studies in Higher Education, 42(9), 16711685. https://doi.org/10.1080/03075079.2015.1117064

Vygotsky, L. (1978). Mind in society: The development of higher psychological processes. Harvard University Press.

Vygotsky, L. 1981. The genesis of higher mental functions. In Wertsch, J. (Ed.), The Concept of Activity in Soviet Psychology, pp. 144-188. M.E. Sharpe.

Williams, A. N., \& Yah, A. N. (2013). One semester of speaking tasks: An experimental approach with low proficiency students. Pertanika Journal of Social Science \& Humanities, 21(4), $1583-1593$. 
Design Principles of a Responsive Pedagogical Model for Multimodal Skills of Oral Presentations

\section{APPENDIX A. Conceptual Map for Stage 3 in RMO2P: Analysing}

Watch the assigned video in groups. Analyse the presentation using the guidelines provided.

Name of presenter:

Topic:

Specific purpose (eg. to inform..., to persuade..., to entertain..., to express...):

3 main points:

1)

2)

3)

Description of audience:

1)

2)

$\begin{array}{cc}\text { Components of multimodal } & \text { Analysis } \\ \text { oral presentation skills } & \end{array}$

\section{Introduction}

Are attention and interest gained?

Is the topic introduced clearly?

Is credibility established?

Is body of speech previewed?

\section{Content}

Is the topic suitable for the audience?

Is the specific purpose identified and achieved?

Are the main points identified clearly?

Are the main points supported with appropriate and credible material?

\section{Organization}

Does the speech have a clear introduction, body and conclusion?

Is a suitable organization pattern utilized?

Are connectives used to support organization?

Conclusion

Is central idea(s) reinforced?

Is the conclusion related to audience?

\section{Coordination}

Is speech completed within time limit?

Are transitions between members smooth?

\section{Linguistic ability}

Is the language accurate?

Is the vocabulary appropriate?

Are the expressions appropriate? 
Oral ability

Is voice used effectively?

Is the articulation clear?

Are pauses and emphases strategic?

Visual engagement ability

Do the visuals effectively support content?

Are the visuals explained?

\section{Gestural ability}

Is eye contact maintained?

Is the posture appropriate/ confident?

Are the physical actions effective?

\section{Overall credibility}

Is the presenter familiar with the content?

Is the presenter confident?

Is credibility maintained?

Has the audience attention been captured?

Does the grooming/ appearance enhance credibility?

\section{Overall, the presenter HAS/ HAS NOT achieved his aims.}

\begin{tabular}{|l|l|l|}
\hline Strengths: & Weaknesses: & Suggestions to improve: \\
& & \\
& & \\
\end{tabular}

